\title{
Arsenic enrichment and organomineralizations in microbial mats of the Dead Sea shores
}

\author{
CAMILLE THOMAS ${ }^{1}$, NUPHAR GEDULTER ${ }^{2}$, YANIV \\ DARVASI $^{2}$, IRINA BUNDELEVA ${ }^{3}$, PROF. ADI \\ TORFSTEIN $^{2}$, AMOTZ AGNON ${ }^{2}$ AND DANIEL \\ ARIZTEGUI $^{1}$ \\ ${ }^{1}$ University of Geneva \\ ${ }^{2}$ Hebrew University of Jerusalem \\ ${ }^{3}$ University of Bourgogne Franche-Comté \\ Presenting Author: camille.thomas@unige.ch
}

The Dead Sea extreme hypersaline environment supports the development of microbial mats in networks of freshwater-diluted brine pools at the shores of the lake. We hypothesize that these oases of life share similarities with those that have allowed the formation of stromatolites along ancient Holocene to Pleistocene shorelines of the lake. These stromatolites are formed of aragonite lamina and sometimes enriched in metals like manganese (Buchbinder, 1981; Druckman, 1981). Since stromatolites are used to reconstruct the Dead Sea paleoshorelines (e.g. Abu-Ghazleh \& Kempe, 2009), the process of their formation must be well constrained, which is currently not the case.

In order to tackle this issue, we investigate a system of living and fossilizing aragonite-rich microbial mats at the shore of the currently retreating Dead Sea. They emerge from ponds and sinkholes formed by the dissolution of salt by circulating freshwater. The salinity of these ponds varies from 28 to 47 g.L of total dissolved salt (ten times less saline than the Dead Sea). Thick exopolymeric substances (EPS) develop in some of them. By combining imaging techniques (confocal epi-fluorescence microscopy, SEM) with chemical, biological and mineralogical mapping (EDX, $\mu$ XRF and EPMA), we identified patterns of transformation of EPS into Mg-Si-rich matrix and finally $\mathrm{CaCO}_{3}$. We suspect that the combination of anoxygenic and oxygenic photosynthesis drives the transformation of EPS into aragonite, therefore providing a biological process for the mineralization of microbial mats into stromatolites in the Dead Sea. We also highlight a localized enrichment of arsenic in one of the mats, suggesting its microbial cycling possibly coupled to anoxygenic photosynthesis. This would be the first occurrence of such a process in the extreme Dead Sea realm.

Abu-Ghazleh, S., \& Kempe, S. (2009). Geomorphology of Lake Lisan terraces along the eastern coast of the Dead Sea, Jordan. Geomorphology, 108(3-4), 246-263.

Buchbinder B (1981) Morphology, microfabric and origin of stromatolites of the Pleistocene precursor of the Dead Sea, Israel. In: Phanerozoic Stromatolites. Springer, pp. 181-196.

Druckman Y (1981) Sub-Recent Manganese-Bearing Stromatolites Along Shorelines of the Dead Sea. In: Phanerozoic Stromatolites, Case Histories (ed. Monty C). Springer-Berlaf, Berlin-Heidelberg, pp. 197-208. 